www.nature.com/pj

\title{
DSC-FTIR microspectroscopy used to investigate the heat-induced intramolecular cyclic anhydride formation between Eudragit E and PVA copolymer
}

\author{
Shan-Yang Lin, Wen-Ting Cheng, Yen-Shan Wei and Hong-Liang Lin
}

Polymer Journal (2011) 43, 577-580; doi:10.1038/pj.2011.15; published online 9 March 2011

Keywords: DSC-FTIR; ester condensation; Eudragit E; PVA copolymer

\section{INTRODUCTION}

Acrylic resins containing acrylic acid (AA), methyl methacrylate (MMA) or acrylic-methacrylic copolymer are the most commonly used polymeric materials for biomedical and pharmaceutical applications owing to their hydrophilicity and biocompatibility. ${ }^{1-4}$ Recently, a new polyvinyl alcohol (PVA) copolymer designed by copolymerizing AA and MMA with PVA was successfully developed as a capsule shell for filling liquid formulations to enhance the bioavailability of waterinsoluble drugs. ${ }^{5-7}$ PVA was used as a skeleton in the structure of PVA copolymer; MMA and AA were separately copolymerized to increase the hardness of the capsule shell and the solubility in water. Furthermore, the PVA copolymer has also been reported to act as a binder or film-coating agent in pharmaceutical applications. ${ }^{8-10}$ In particular, the oxygen-blocking and light-protective properties of PVA copolymer film have increased its usage in the pharmaceutical industry. ${ }^{9,10}$ The stability of PVA copolymer is another important factor for pharmaceutical applications. Because the stability of PVA copolymer may significantly influence the physico-chemical properties and efficacy of a drug after application of PVA copolymer, accelerated stability tests for PVA copolymer should be performed to predict the storage stability and quality of drug products. Accelerated stress conditions, including heat, humidity and light, have become a popular parameter for evaluating the reliability of drug products within short testing periods. ${ }^{11,12}$

Our previous study provided the first evidence of thermally induced anhydride formation in Eudragit E, a copolymer composed of butyl methacrylate, 2-dimethylaminoethyl methacrylate and MMA in the composition 1:2:1. ${ }^{13}$ PVA copolymer has also been copolymerized by $\mathrm{AA}$ and MAA with PVA, ${ }^{5-7}$ but the thermal stability has not yet been investigated. In the present study, a highly specialized and powerful Fourier transform infrared (FTIR) microspectroscopy equipped with a differential scanning calorimeter (DSC) was used to examine the thermal stability of PVA copolymer. Eudragit E was used for comparison.

\section{EXPERIMENTAL PROCEDURE}

Materials

PVA copolymer (POVACOAT, Type F, Mw: 40000) and Eudragit E 100 (Mw: 150000 ) were kindly supplied by Nissin Kasei (Osaka, Japan) and Evonik Industries AG (Essen, Germany), respectively. Reagent-grade anhydrous ethanol $(99.9 \%)$ and $\mathrm{KBr}$ cubic crystal $\left(5 \times 5 \times 5 \mathrm{~mm}^{3}\right)$ were purchased from Nakalai Tesque (Kyoto, Japan) and Jasco (Tokyo, Japan).

\section{Preparation of PVA copolymer film and Eudragit E film}

Six percentages (w/v) of ethanolic solution of Eudragit $E$ or aqueous solution of PVA copolymer were separately dropped onto a glass plate. A spin coater (SC-300, EHC, Taiwan, ROC) was used to prepare a uniform/smooth film of each copolymer, which was then vacuum-dried at $60^{\circ} \mathrm{C}$ for $30 \mathrm{~min} .{ }^{13}$ The film thicknesses of the PVA copolymer or Eudragit $\mathrm{E}$ cast onto a glass plate were about 6-8 $\mu \mathrm{m}$, as measured with a digimatic caliper (Mitutoyo, Kanagawa, Japan).

\section{Transmission DSC-FTIR microspectroscopic study}

Each film cast onto the glass plate was carefully peeled off and cut to about $3 \times 3 \mathrm{~mm}^{2}$, then directly sealed between two $\mathrm{KBr}$ plates with a hydraulic press under $200 \mathrm{~kg} \mathrm{~cm}^{-2}$ pressure for $15 \mathrm{~s}$ to form a disc. Next, each sample disc was placed on a hot stage (DSC microscope assembly, FP 84, Mettler, Greifensee, Switzerland). The DSC microscope assembly was then set directly on the stage of an FTIR microscope spectrometer (IRT-5000-16/FTIR-6200, Jasco) with a mercury cadmium telluride detector using a transmission method. The temperature of the DSC microscope assembly was monitored with a central processor (FP $80 \mathrm{HT}$, Mettler). Each sample disc was equilibrated to the starting temperature $\left(30^{\circ} \mathrm{C}\right)$ and then heated to $320^{\circ} \mathrm{C}$ at the rate of $3{ }^{\circ} \mathrm{C} \mathrm{min}-1$ under $25-28^{\circ} \mathrm{C} / 65-75 \%$ relative humidity conditions. The thermal-responsive infrared (IR) spectra were simultaneously recorded over the course of the heating process. ${ }^{13-16}$

\section{RESULTS AND DISCUSSION}

Heat-induced ester condensation in the Eudragit E film

For comparison, an Eudragit E film was examined using DSC-FTIR microspectroscopy. A three-dimensional plot of the transmission FTIR 

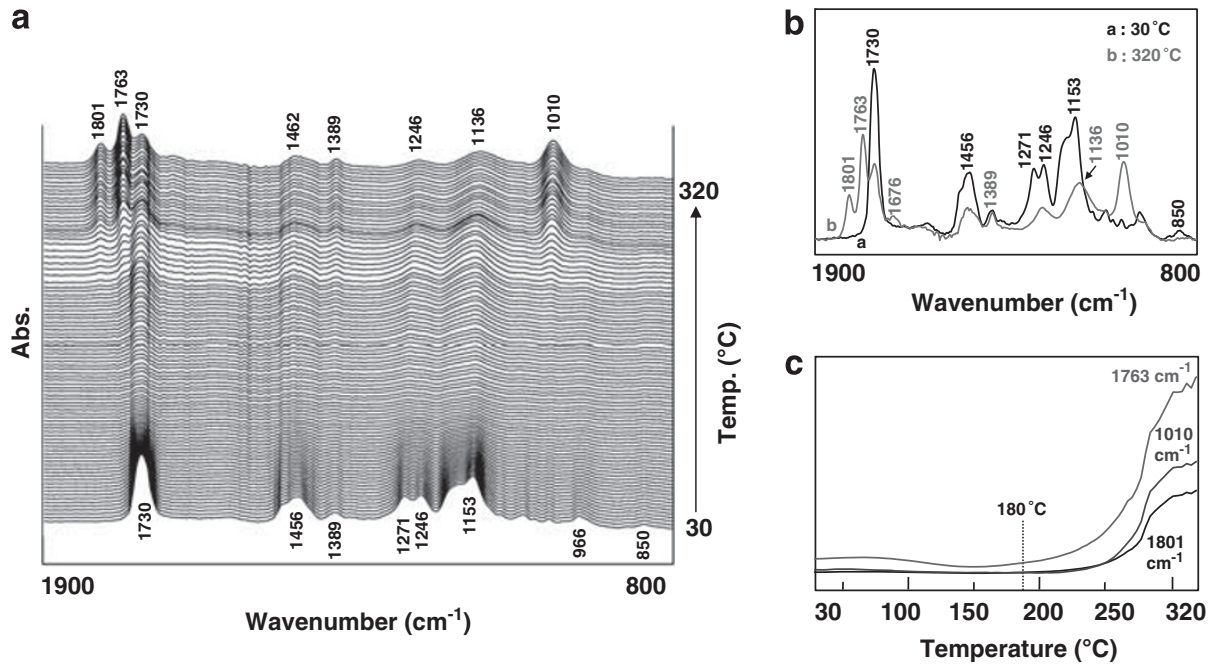

Figure 1 Temperature-dependent three-dimensional plot (a) and comparison (b) of transmission FTIR spectra of Eudragit E film and the changes in intensity of three specific peaks (c).

a Eudragit E

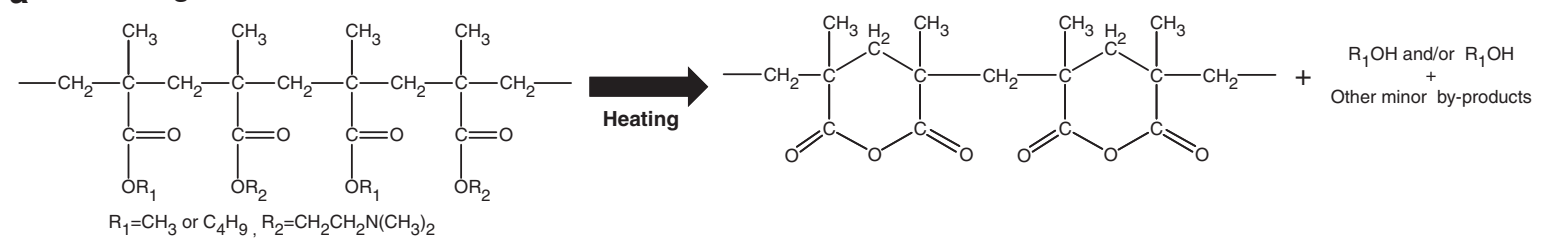

b PVA copolymer
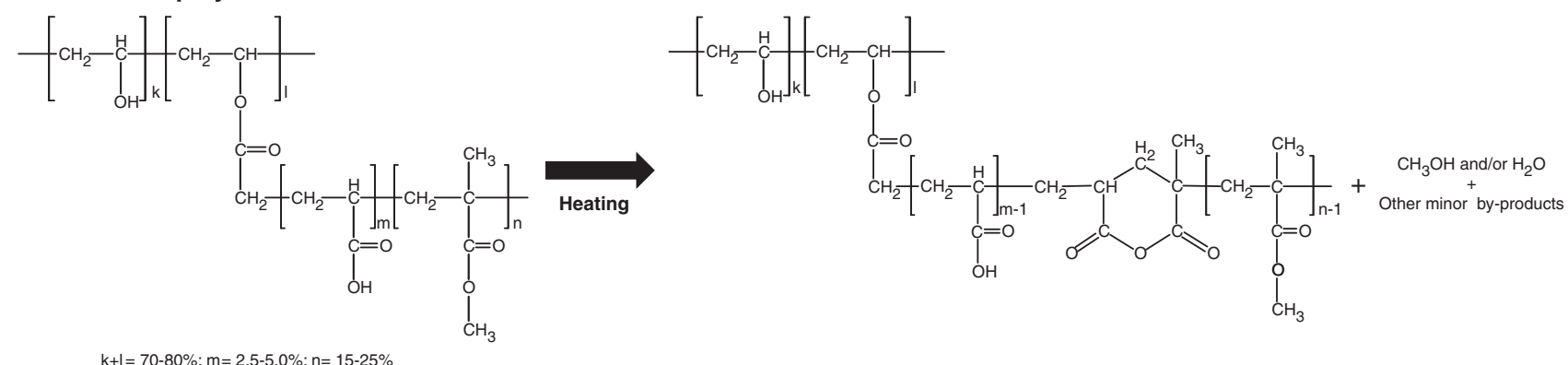

Scheme 1 A proposed process of heat-induced anhydride formation of Eudragit E or PVA copolymer via intramolecular ester condensation. $k+l=70-80 \%$; $m=2.5-5.0 \% ; n=15-25 \%$.

spectra of the Eudragit $\mathrm{E}$ film as a function of temperature in the IR range of 1900 to $800 \mathrm{~cm}^{-1}$ is shown in Figure 1a. Figure $1 \mathrm{~b}$ compares the FTIR spectra of the Eudragit E film at 30 and $320^{\circ} \mathrm{C}$. Several characteristic IR absorption bands and their assignments at the initial temperature $\left(30^{\circ} \mathrm{C}\right)$ are shown: $1730 \mathrm{~cm}^{-1}(\mathrm{C}=\mathrm{O}$ stretching of ester), $1456 \mathrm{~cm}^{-1}$ (C-H bending of methyl), 1271 and $1246 \mathrm{~cm}^{-1}$ (C-O stretching of ester) and $1153 \mathrm{~cm}^{-1}$ (C-N stretching of aliphatic amine and/or $\mathrm{C}-\mathrm{O}$ stretching of ester). ${ }^{17,18}$

As shown in Figures 1a and c, the wavenumber and peak intensity of the IR spectra changed significantly with the increase of temperature. Once the Eudragit E film was heated beyond $180^{\circ} \mathrm{C}$, the intensities of three specific peaks at 1801, 1763 and $1010 \mathrm{~cm}^{-1}$ began to increase with temperature, which is consistent with our previous report. ${ }^{13}$ The new peaks at 1801 and $1763 \mathrm{~cm}^{-1}$ were assigned to the symmetric and asymmetric $\mathrm{C}=\mathrm{O}$ stretching vibrations in the anhydride, implying that anhydride formation occurred in the Eudragit $\mathrm{E}$ film during the heating process. ${ }^{17-19}$ In addition, the intensity of a new peak at $1010 \mathrm{~cm}^{-1}$ due to the asymmetric stretching mode of C-O-C also increased beyond $180^{\circ} \mathrm{C}$, strongly supporting the cyclic anhydride formation via ester condensation in the Eudragit E film. This result is consistent with the report by Pretsch et al., ${ }^{18}$ in which the carbonyl stretching vibration of six-membered cyclic anhydrides exhibited unique peaks at 1800 and $1760 \mathrm{~cm}^{-1}$, rather than at 1850 and $1775 \mathrm{~cm}^{-1}$ as was shown by five-membered cyclic anhydrides. This result confirms the formation of six-membered cyclic anhydrides in the Eudragit E film during the heating process. Scheme 1 shows a possible schematic mechanism of the heat-induced anhydride formation by ester condensation in the Eudragit $\mathrm{E}$ film. Here, the ester condensation was dependent solely on heat effects without any catalyst or initiator. 
a
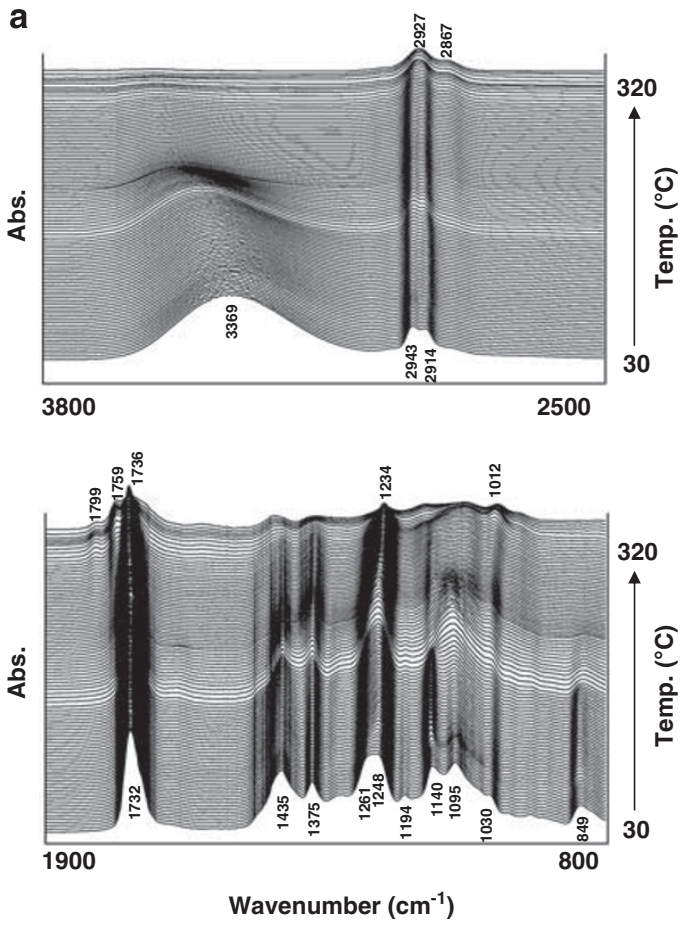

b
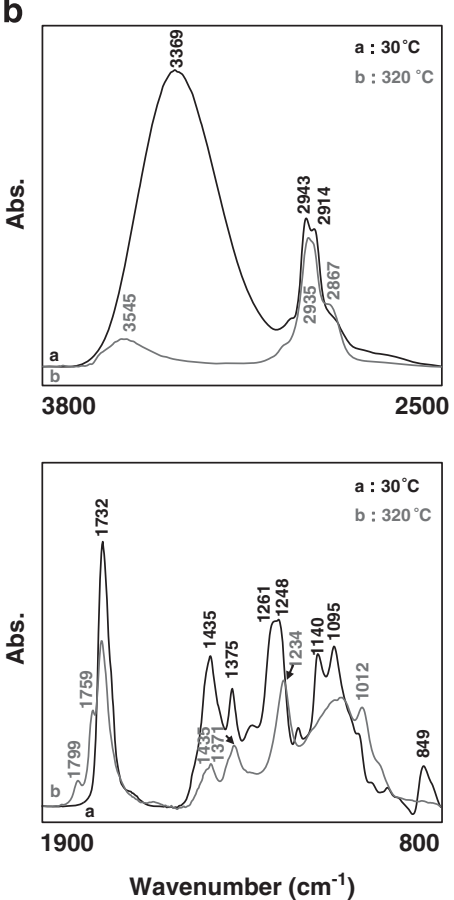

Figure 2 Temperature-dependent three-dimensional plot (a) and comparison (b) of transmission FTIR spectra of the PVA copolymer.

Heat-induced ester condensation in the PVA copolymer film

The temperature-dependent three-dimensional plot of the FTIR spectra of PVA copolymer in the IR ranges of $3800-2500 \mathrm{~cm}^{-1}$ and $1900-800 \mathrm{~cm}^{-1}$ is shown in Figure 2a. Two FTIR spectra of the PVA copolymer film before and after heat treatments are shown in Figure $2 \mathrm{~b}$. Before heat treatment $\left(30^{\circ} \mathrm{C}\right)$, several IR characteristic peaks were observed (Figures $2 \mathrm{a}$ and $\mathrm{b}$ ). The broad peak around $3369 \mathrm{~cm}^{-1}$ was due to the hydrogen-bonded $\mathrm{OH}$ stretching vibrations and/or the absorbed moisture in the sample, and the peaks at 2943 and $2914 \mathrm{~cm}^{-1}$ corresponded to the $\mathrm{C}-\mathrm{H}$ stretching from the alkyl groups. In the range of $1900-800 \mathrm{~cm}^{-1}$, peaks at $1732 \mathrm{~cm}^{-1}(\mathrm{C}=\mathrm{O}$ stretching), $1435 \mathrm{~cm}^{-1}$ (C-H bending), 1261 and $1248 \mathrm{~cm}^{-1}(\mathrm{C}-\mathrm{O}$ stretching), $1100-1000 \mathrm{~cm}^{-1}$ (C-O stretching in $\mathrm{C}-\mathrm{O}-\mathrm{H}$ groups and COC groups) and $849 \mathrm{~cm}^{-1}$ (C-H rocking mode) were observed. ${ }^{20,21}$ Notably, the peak at $1140 \mathrm{~cm}^{-1}$ has been reported to be related to the crystalline $\mathrm{C}-\mathrm{O}$ stretching vibration of PVA, which depends on the degree of crystallization in the PVA copolymer. ${ }^{22,23}$

After heating to $320^{\circ} \mathrm{C}$, four new peaks at $3545,1799,1759$ and $1012 \mathrm{~cm}^{-1}$ appeared, and the peak at $849 \mathrm{~cm}^{-1}$ vanished. In particular, the appearance of IR peaks at 1799,1759 and $1012 \mathrm{~cm}^{-1}$ was similar to the results for the thermally treated Eudragit E film, strongly suggesting cyclic anhydride formation via ester condensation in the film of PVA copolymer. The observation of the peaks at both 1799 and $1759 \mathrm{~cm}^{-1}$ in the IR spectrum of the PVA copolymer also confirmed the formation of six-membered cyclic anhydrides. ${ }^{18}$ The proposed process of thermally induced anhydride formation for PVA copolymers via ester condensation is depicted in Scheme 1. The sharp peak at $1140 \mathrm{~cm}^{-1}$ almost disappeared from the IR spectrum of the $320^{\circ} \mathrm{C}$ heated PVA copolymer, which indicates that the thermally induced ester condensation also altered the crystallinity of the PVA in the PVA copolymer.

Temperature-dependent changes in the peak intensity of several representative IR bands for the cast film of PVA copolymer are shown
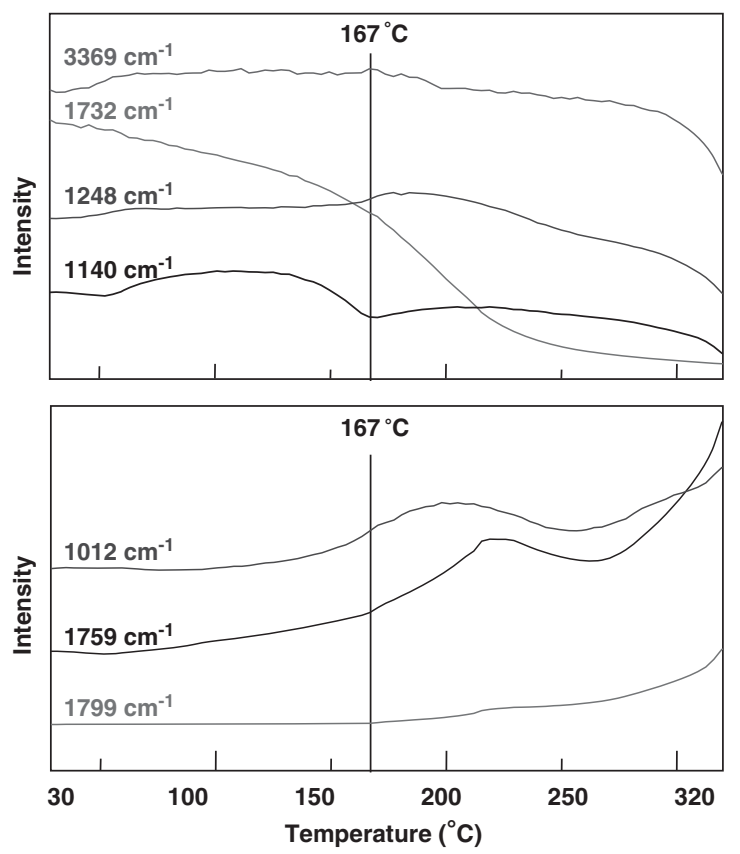

Figure 3 Changes in intensity of the representative IR peaks for PVA copolymer.

in Figure 3. Clearly, the peak indicating ester disappearance at $1732 \mathrm{~cm}^{-1}$ gradually decreased as a function of temperature. However, the three peak intensities at 1799, 1759 and $1012 \mathrm{~cm}^{-1}$ increased slightly with temperature. A marked change in peak intensity was found at $167^{\circ} \mathrm{C}$, indicating that beyond this temperature ester condensation occurred in the PVA copolymer. In a continuous process of ester condensation, several changes in peak intensity were evident 
from the contour profile (Figure 2). The crystallinity-sensitive peak at $1140 \mathrm{~cm}^{-1}$ also showed a marked downward tendency.

\section{Difference between Eudragit E and PVA copolymer}

In order to confirm the cyclic anhydride formation in both polymers, rather than non-cyclic anhydride formation, the peak intensity ratios of the asymmetric and symmetric $\mathrm{C}=\mathrm{O}$ stretching vibrations in the anhydride were calculated because both bands depend on the 'cyclic' and 'non-cyclic' character of the anhydride. ${ }^{24,25}$ It has been reported that the symmetric $\mathrm{C}=\mathrm{O}$ stretching band at high frequency is stronger than the asymmetric $\mathrm{C}=\mathrm{O}$ stretching band at low frequency for a noncyclic anhydride, and that the opposite is true for a cyclic anhydride. ${ }^{25} \mathrm{In}$ the present study, the peak intensity ratios of $1763 \mathrm{~cm}^{-1} / 1801 \mathrm{~cm}^{-1}$ for Eudragit E and $1759 \mathrm{~cm}^{-1} / 1799 \mathrm{~cm}^{-1}$ for the PVA copolymer were about 2.47 and 2.02 , respectively. A high peak intensity ratio $(>1.0)$ implies that the cyclization due to intramolecular ester condensation was predominantly responsible for the cyclic anhydride formation occurring in the film of Eudragit E or PVA copolymer. ${ }^{20,26}$ In addition, the magnitude of these peak intensity ratios might be explained by the different numbers of reaction sites in both copolymers. As shown in Scheme 1, the amount of anhydride formed in the film of Eudragit E seemed to be higher than that in PVA copolymer during the heating process.

\section{CONCLUSION}

Both Eudragit E and PVA copolymer were able to form six-membered cyclic anhydrides via intramolecular ester condensation while being heated. The amount of anhydride formed in the film of Eudragit E seemed to be higher than that formed in the PVA copolymer during the heating process. Therefore, we conclude that a powerful thermal FTIR microspectroscopy is valuable for rapid detection of the thermal stability of the Eudragit E and PVA copolymer films in real time.

1 Jagur-Grodzinski, J. Polymeric gels and hydrogels for biomedical and pharmaceutical applications. Polym. Adv. Technol. 121, 27-47 (2010).

2 Gallardo, D., Skalsky, B. \& Kleinebudde, P. Controlled release solid dosage forms using combinations of (meth)acrylate copolymers. Pharm. Dev. Technol. 13, 413-423 (2008).

3 Frazer, R. Q., Byron, R. T., Osborne, P. B. \& West, K. P. PMMA: an essential material in medicine and dentistry. J. Long Term Eff. Med. Implants 15, 629-639 (2005).

4 Kadian, S. S. \& Harikumar, S. L. Eudragit and its pharmaceutical significance, http:// www.pharmainfo.net/satishsinghkadian/publications/eudragit-and-its-pharmaceuticalsignificance.
5 Hoshi, N., Ogura, T., Shimamoto, T. \& Uramatsu, S. Development of PVA copolymer capsules. Pharm. Tech. Jpn. 19, 1-12 (2003).

6 Hoshi, N., Ogura, T., Shimamoto, T. \& Uramatsu, S. Development of PVA copolymer capsules. Pharm. Tech. Eur. 16, 37-46 (2004).

7 Hoshi, N., Kida, A., Hayashi, T. \& Murakami, Y. Creating PVA copolymer capsules. Pharm. Technol. Eur. 20, 17-25 (2008).

8 Fujii, T., Noami, M., Tomita, K. \& Furuya, Y. Development of a new coating agent, PVA copolymer (I). Pharm. Tech. Jpn. 21, 257-261 (2005).

9 Fujii, T., Noami, M., Tomita, K. \& Furuya, Y. PVA copolymer: the new coating agent. Pharm. Technol. Eur. 20, 32-39 (2008).

10 Kojo, A., Noami, M. \& Funaki, T. Development of a new coating agent, PVA copolymer (II). Pharm. Tech. Jpn. 25, 369-374 (2009).

11 Klick, S., Muijselaar, P. G., Waterval, G., Eichinger, T., Korn, C., Gerding, T. K., Debets, A. J., Griend, C. S., Beld, C. V. D., Somsen, G. W. \& DeJong, G. J. Toward a generic approach for stress testing of drug substances and drug products. Pharm. Tech. 29, 48-66 (2005).

12 Baertschi, S., Alsante, K. \& Reed, R. A. (eds). Pharmaceutical Stress Testing: Predicting Drug Degradation (Taylor \& Francis, New York, NY, 2005).

13 Lin, S. Y., Yu, H. L. \& Li, M. J. Formation of six-membered cyclic anhydrides by thermally induced intramolecular ester condensation in Eudragit E film. Polymer 40, 3589-3593 (1999).

14 Cheng, Y. D. \& Lin, S. Y. Isothermal Fourier transform infrared microspectrosopic studies on the stability kinetics of solid-state intramolecular cyclization of aspartame sweetener. J. Agric. Food Chem. 48, 631-635 (2000).

15 Wang, S. L., Lin, S. Y., Chen, T.F. \& Cheng, W.T. Eudragit E accelerated the diketopiperazine formation of enalapril maleate determined by thermal FTIR microspectroscopic technique. Pharm. Res. 21, 2127-2132 (2004).

16 Gao, G. Y. \& Lin, S. Y. Thermodynamic investigations of nitroxoline sublimation by simultaneous DSC-FTIR method and isothermal TG analysis. J. Pharm. Sci. 99, 255-261 (2010).

17 Pavia, D. L., Lampman, G. M. \& Kriz, G. S. (eds). Introduction to Spectroscopy: A Guide for Students of Organic Chemistry 13-80 (W. B. Saunders, Philadelphia, PA, 1979).

18 Pretsch, E., Seibl, J. \& Simon, W. (eds). Tables of Spectral Data for Structure Determination of Organic Compounds 2nd edn, 15-1280 (Springer-Verlag, Berlin, 1989).

19 Wade, L. G. (ed.). Organic Chemistry 1030-1034 (Prentice-Hall, Englewood Cliffs, NJ, 1987).

20 Arndt, K. F., Richter, A., Ludwig, S., Zimmermann, J., Kressler, J., Kuckling, D. \& Adler, H. J. Poly(vinyl alcohol)/poly(acrylic acid) hydrogels: FT-IR spectroscopic characterization of crosslinking reaction and work at transition point. Acta Polymer. 50, 383-390 (2000).

21 Mansur, H. S., Sadahira, C. M., Souza, A. N. \& Mansur, A. P. FTIR spectroscopy characterization of poly (vinyl alcohol) hydrogel with different hydrolysis degree and chemically crosslinked with glutaraldehyde. Mater. Sci. Eng. C 28, 539-548 (2008).

22 Lee, J., Lee, K. J. \& Jang, J. Effect of silica nanofillers on isothermal crystallization of poly(vinyl alcohol): in-situ ATR-FTIR study. Polymer Test. 27, 360-367 (2008).

23 Kenney, J. F. \& Willcockson, W. G. Structure-property relationships of poly(vinyl alcohol). III. Relationships between stereo-regularity, crystallinity, and water resistance in poly(vinyl alcohol). J. Polym. Sci. Polym. Chem. 4, 679-698 (1966).

24 Iqbal, M., Chuai, C., Huang, Y. \& Che, C. Modification of low-density polyethylene by graft copolymerization with maleic anhydride and blends with polyamide 6. J. Appl. Polym. Sci. 116, 1558-1565 (2010).

25 Yang, C. Q., Xu, Y. \& Wang, D. FT-IR spectroscopy study of the polycarboxylic acids used for paper wet strength improvement. Ind. Eng. Chem. Res. 35, 4037-4042 (1996).

26 Socrates, G. Infrared Characteristic Group Frequencies 2nd edn (Wiley, New York, NY, 1994). 